\title{
Control Features of 3D Deflector under Different Braking Conditions
}

\author{
Aistis AUGUSTAITIS*, Sylvester DJOKOTO**, Vytautas JURÉNAS***, \\ Genadijus KULVIETIS $* * * *$ \\ *Vilnius Gediminas Technical University, Saulètekio 11, 10223 Vilnius, Lithuania, E-mail: aistis.augustaitis@vgtu.lt \\ **Kaunas University of Technology, K. Donelaičio 73, 44249 Kaunas, Lithuania, E-mail: sylvester.djokoto@ktu.lt \\ ***Kaunas University of Technology, K. Donelaičio 73, 44249 Kaunas, Lithuania, E-mail: vytautas.jurenas@ktu.lt \\ ****Vilnius Gediminas Technical University, Sauletekio 11, 10223 Vilnius, Lithuania, E-mail: genadijus.kulvietis@vgtu.lt \\ cross $^{\text {ref }}$ http://dx.doi.org/10.5755/j01.mech.24.5.20316
}

\section{Introduction}

The piezoelectric actuator is a unique device because it has these major advantages: high displacement resolution, short response time, high force and mass ratio, simple construction, compactness, lightness. These features make the actuator very attractive in wide region of application such as an ultra-precision component machining, tunable optical devices, biomedicine, robotics and so on [1]. Electrorheological and magnetorheological fluids (ERF and MRF) can be used to shorten the stopping time and distance of movable link [2].

\section{Primary data}

The experimental model (Fig. 1) of 3D deflector is used to create the structural scheme of theoretical model. Despite a movable link shape in experimental model a full hollow ball is chosen to use in theoretical model (Fig. 2). The ball is manufactured from steel. The inside radius of piezoelectric ring is $19,5 \mathrm{~mm}$.

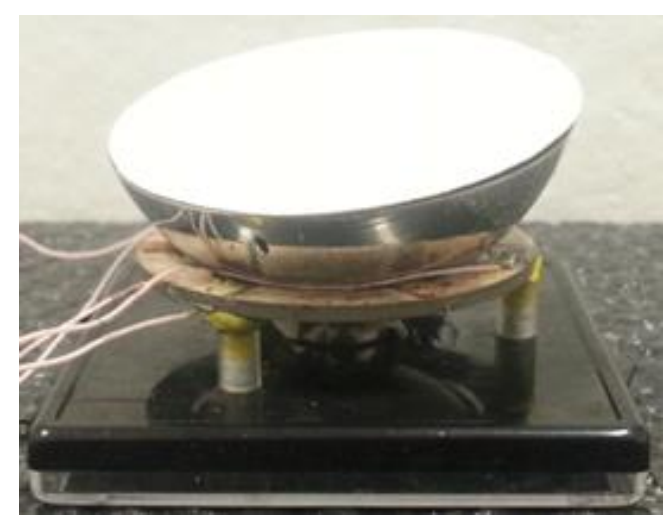

Fig. 1 Experimental model of 3D deflector

A wide surface of the rotor can become greasy after a contact with smart fluid. A sliding friction coefficient reduces dramatically if the greasy surface reaches the zone of 3 contact points. These points are equally located on the surface of ring end in circumferential direction. Seeking to ensure a high frictional value the points are made of epoxy resin. The angular displacement of the ball must be constrained and the radius of smart fluid layer has to be small

$$
I=0,4\left(R_{1}\right)^{2} \cdot \frac{4}{3} \pi\left(R_{1}\right)^{3} \rho-0,4\left(R_{1}-t_{1}\right)^{2} \cdot \frac{4}{3} \pi\left(R_{1}-t_{1}\right)^{3} \rho,
$$

enough too. A concave shape of bottom electrode end is approximated as circle surface; which radius is $R$ (Table 1). It is important to increase a contact force between the rotor and a fixed ring of piezoelectric actuator in order to improve control properties. According to this a bottom electrode is made to perform permanent magnet features too when using with ERF. The electrode has to be changed into an electromagnet for MRF activation. A piezoelectric ring is fixed using 3 cylindrical supports.

Table 1

Dimensions of theoretical model

\begin{tabular}{|c|c|}
\hline Dimensions & Value $(\mathrm{mm})$ \\
\hline$R_{1}$ & 30 \\
\hline$t_{1}$ & 1,5 \\
\hline$R$ & 7,5 \\
\hline$t$ & 0,5 \\
\hline
\end{tabular}

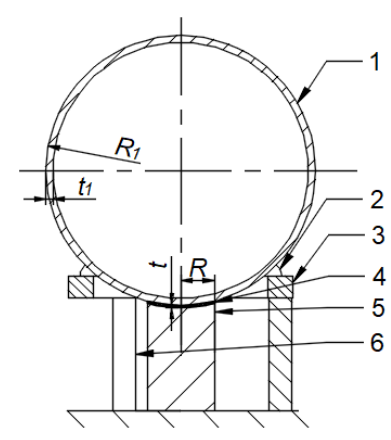

Fig. 2 Theoretical model of 3D deflector. $1-$ a spherical rotor (ball), 2 - a contact point, 3 - a piezoelectric ring (transducer), 4 - a smart fluid layer, 5 - a permanent magnet and a bottom electrode too for using with ERF or an electromagnet for using with MRF, $6-\mathrm{a}$ support for the transducer.

The area of approximated concave surface $A$ is $1,77 \cdot 10^{-4} \mathrm{~m}^{2}$ (Eq. (1)). The initial values of the ball angular speed $\omega_{0}$ are chosen: $0,2,0,6$ and $1,0 \mathrm{rad} / \mathrm{s}$. The initial values of the fluid shear rate $\gamma_{0}$ (Eq. (2)) are: $12,36,60 \mathrm{~s}^{-1}$ according to the last statement. The ball moment of inertia $I$ is equal to $73 \cdot 10^{-6} \mathrm{~kg} \cdot \mathrm{m}^{2}$ (Eq. (3)).

$$
\begin{aligned}
& A \cong \pi R^{2} . \\
& \gamma_{0}=\omega_{0} R_{1} / t .
\end{aligned}
$$


where: $R_{1}$ is the outside radius of the rotor; $t_{1}$ is the wall thickness of the rotor; $\rho$ is steel density, which is chosen $7850 \mathrm{~kg} / \mathrm{m}^{3} ; R$ is the projected radius of lower electrode; $t$ is the thickness of smart fluid layer.

\section{Approximation of ERF and MRF rheological charac- teristics}

LID $3354 \mathrm{~s}$ is chosen as ERF to simulate additional friction pair with the ball. The experimental characteristics of the fluid are shown in Figs. 3 and 4 [3, 4]. A second degree polynomial function (Eq. (4)) is used to shift the experimental curve of viscosity $\mu$. The experimental curve of yield stress $\tau_{Y}$ is also changed into a quadratic function (Eq. (5)) in order to get similar shapes. A statement that linear function should be used to shift the last experimental graph [3] is omitted. It is considered that LID 3354s viscosity and yield stress depend only on electric field strength $E$.

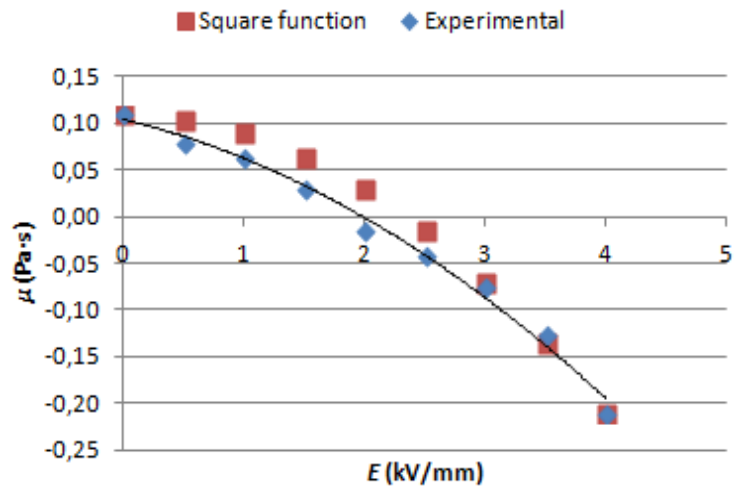

Fig. 3 Viscosity graphs of the ERF

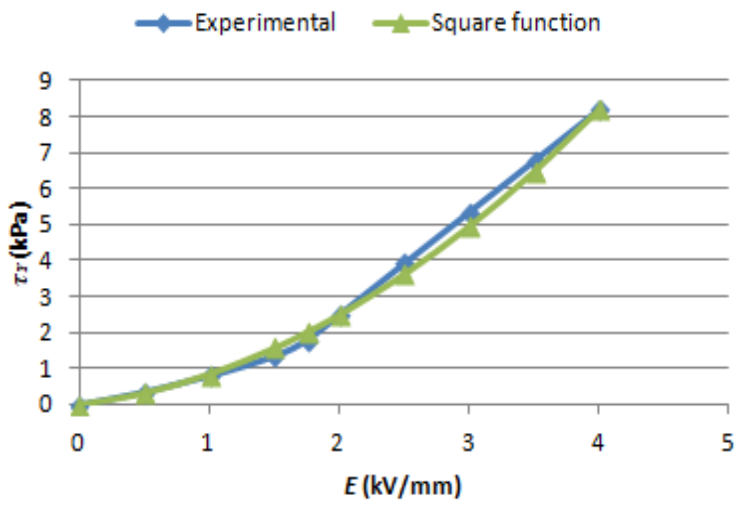

Fig. 4 Yield stress graphs of the ERF

$$
\begin{aligned}
& \mu(E)=\mu_{0}-C_{\mu} E^{2}=0,11-2 \cdot 10^{-8}\left(10^{3} \cdot E\right)^{2} . \\
& \tau_{Y}(E)=0,4 E^{2}+0,45 E
\end{aligned}
$$

where: $\mu_{0}$ is initial viscosity of the ERF, when $E$ is $0 ; C_{\mu}$ is ERF constant in viscosity function.

Suspension 140CG is chosen as MRF to model additional friction pair with the ball also. The experimental characteristics of the fluid are illustrated in Figs. 5 and 6 [5]. The experimental curve of shear stress because of viscosity $\tau_{\mu}$ is almost flat. According to this a linear function (Eq. (6)) is chosen to shift the curve. After approximation the viscosity of the fluid becomes independent of shear rate $\gamma$ and magnetic field strength $H$ too (Eq. (10)). The experimental curve of yield stress depends only on the field strength and can be replaced with a quadratic function (Eq. (7)).

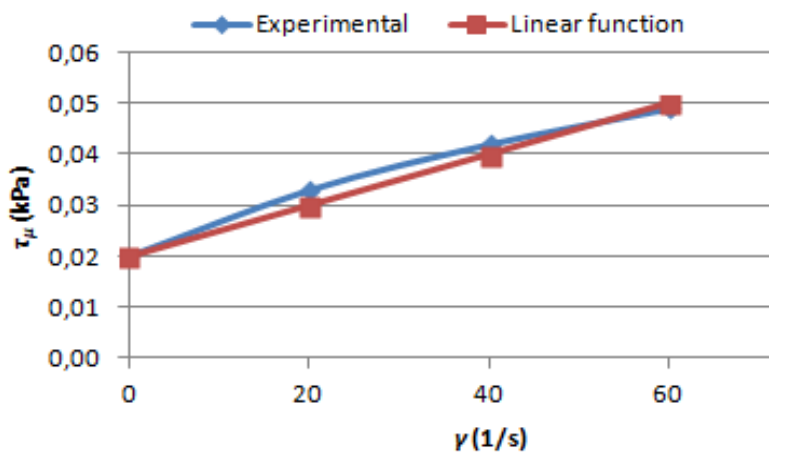

Fig. 5 MRF shear graphs because of viscosity

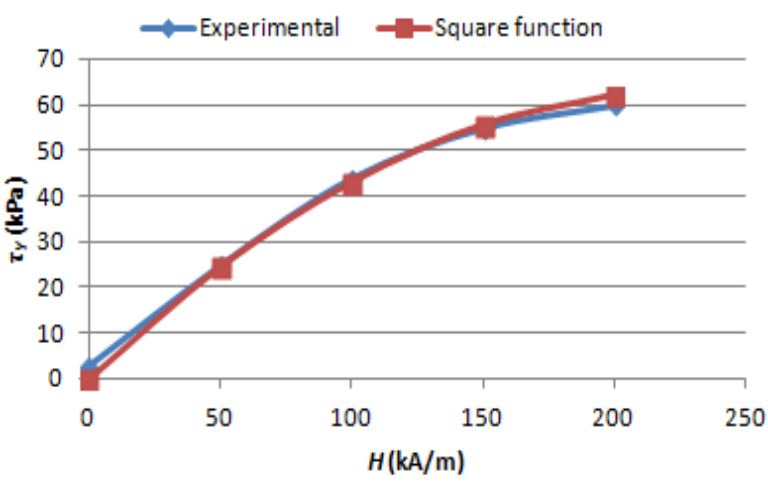

Fig. 6 Yield stress graphs of the MRF

$\tau_{\mu}(\gamma)=0,02+0,0005 \gamma$.

$\tau_{Y}(H)=-0,0012 H^{2}+0,55 H$,

Using electric field strength, the chaotic positions of polarized particles can be changed into an anisotropic structural block in ERF. This action increases the shear stress of ERF [3]. MRF induction and shear features have a lot of common in comparison to ERF [6]. Except that magnetic field strength is needed to activate MRF. The average motion speed for block creation and response time $T$ depends on exterior field strength. Hyperbolic functions (Eqs. (8-9)) are chosen to model the mentioned dependences (Figs. 7-8) using the newest references with appropriate experimental data $[3,6]$. In a conception of the chosen numerical simulation is considered that an exterior field strength is changing linearly from zero to a nominal value over response time period despite that the field strength can reach its nominal value almost instantly in a practical case.

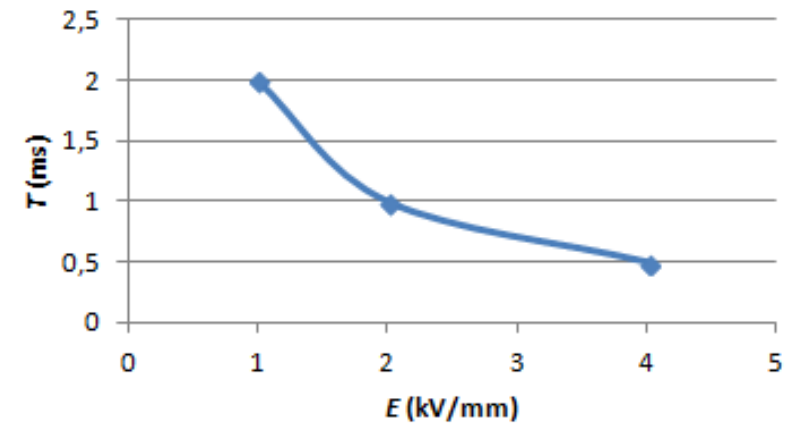

Fig. 7 Response time graph of the ERF 


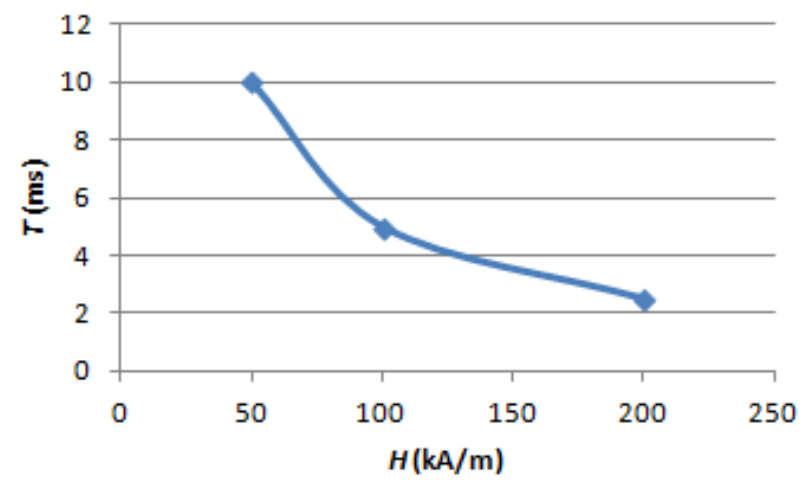

Fig. 8 Response time graph of the MRF

$T(E)=2 / E .$,

$T(H)=500 / H$.

A GER fluid can be used to get the higher values of the shear yield stress. Its action is explained by giant electrorheological effect [7].

\section{Summary of stepped approximation algorithm and simulation results}

Firstly, initial kinetic energy of the ball should be evaluated. Then a relation of the friction coefficient versus

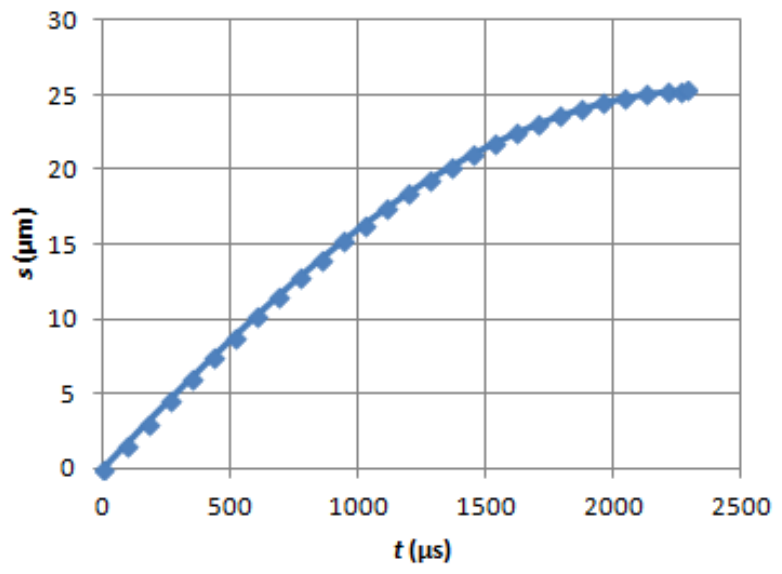

Fig. 9 Path graph of braking with ERF [8]

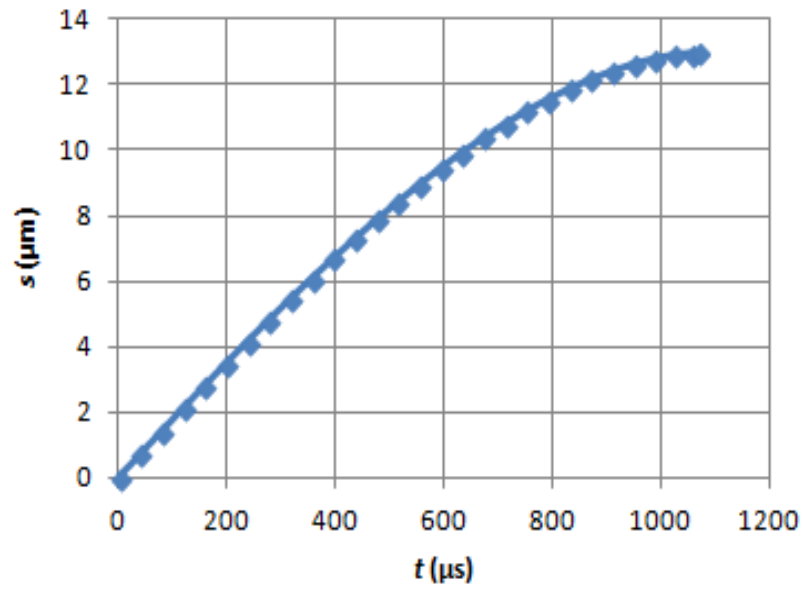

Fig. 10 Path graph of braking with MRF [8] a sliding speed is needed to evaluate. The work because of friction and the work because of fluid shear are negative. They should be counted at each time period of the motion and summed. A negative work of smart fluid is a multiplication of equivalent shear stress, active area of suspension $A$ and a tangential shear displacement. A friction work is a multiplication of normal contact force, friction coefficient and tangential shear displacement. Final kinetic energy of the ball is a subtraction of initial kinetic energy and evaluated negative works until that moment. The evaluation of stopping distance is finished when final kinetic energy or tangential speed of the ball becomes equal to 0 . The most important property of approximation is a regular time step, except the motion at the end. Total negative work after onetime period shouldn't be bigger than $10 \%$ of the initial kinetic energy in order to get quite accurate results of the stepped approximation [8]. Stopping time or distance differences in comparison to results with a half time step of regular, which is determined using a condition above, is up to $5 \%$ [8].

Graphical results of braking path, velocity and acceleration using chosen fluids are given in figures 9-14 after simulations. The properties for braking with electrorheological fluid LID 3354s are $\omega_{0}=0,6 \mathrm{rad} / \mathrm{s}$ and $E=2 \mathrm{kV} / \mathrm{mm}$. The properties for braking with magnetorheological fluid $140 \mathrm{CG}$ are $\omega_{0}=0,6 \mathrm{rad} / \mathrm{s}$ and $H=100 \mathrm{kA} / \mathrm{m}$.

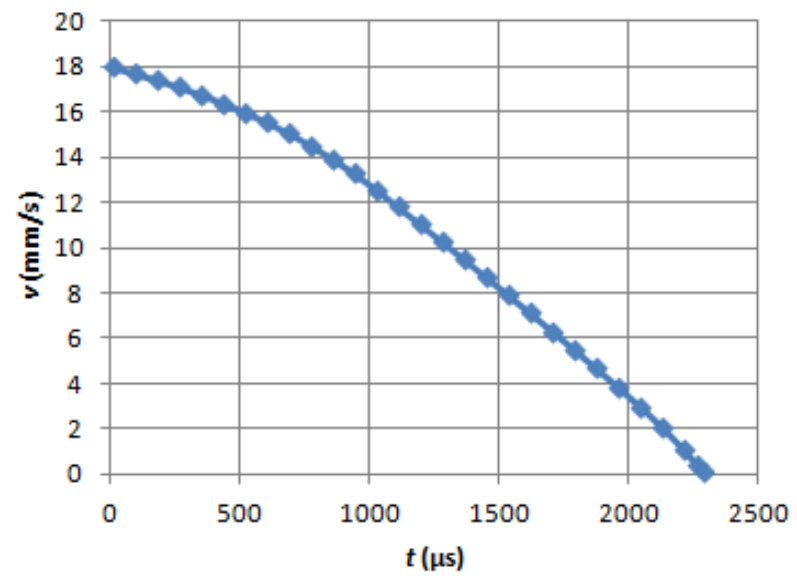

Fig. 11 Velocity graph of braking with ERF [8]

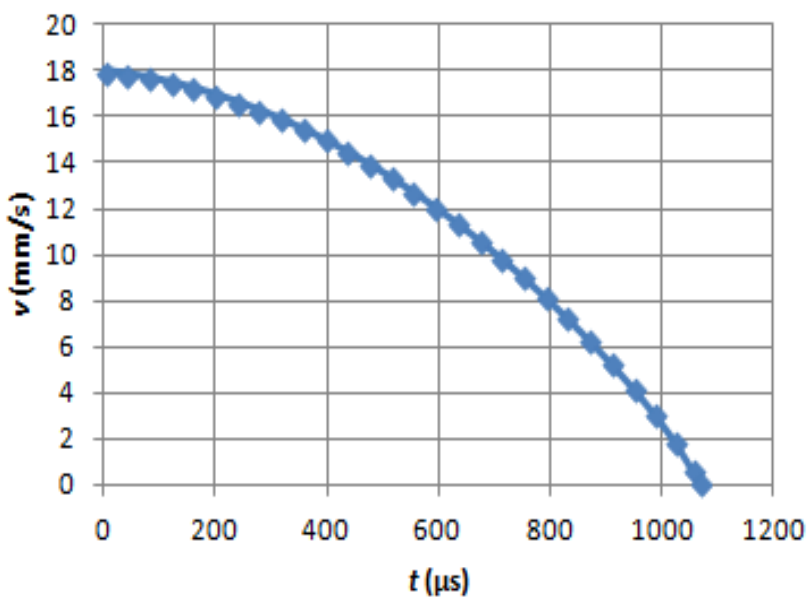

Fig. 12 Velocity graph of braking with MRF [8] 


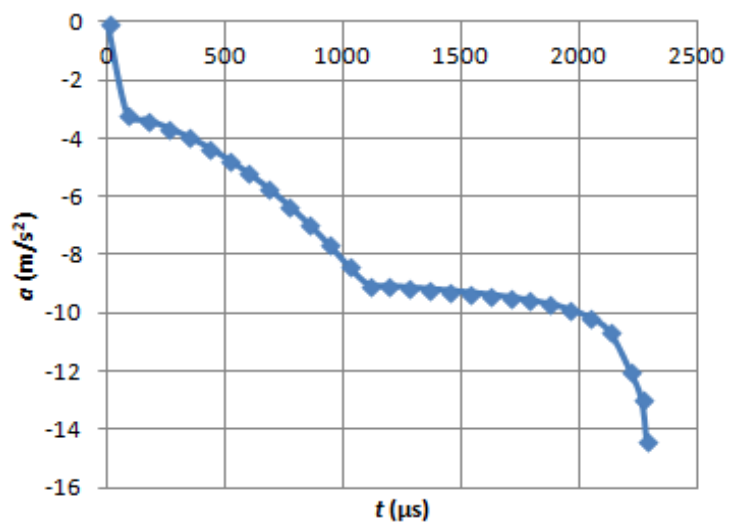

Fig. 13 Acceleration graph of braking with ERF [8]

Most important results of various brake simulations using the chosen fluids are presented in the Tables 27.

Table 2

Braking of the rotor with ERF at low initial speed [8]

\begin{tabular}{|l|l|l|l|}
\hline$\omega_{0}(\mathrm{rad} / \mathrm{s})$ & \multicolumn{3}{|c|}{0,2} \\
\hline$E(\mathrm{kV} / \mathrm{mm})$ & 0 & 2 & 4 \\
\hline Braking time $(\mu \mathrm{s})$ & 1546 & 985 & 523 \\
\hline Braking distance $(\mu \mathrm{m})$ & 5,04 & 3,67 & 2,18 \\
\hline
\end{tabular}

Table 3

Braking of the rotor with ERF at medium initial speed [8]

\begin{tabular}{|l|c|c|c|}
\hline$\omega_{0}(\mathrm{rad} / \mathrm{s})$ & \multicolumn{3}{|c|}{0,6} \\
\hline$E(\mathrm{kV} / \mathrm{mm})$ & 0 & 2 & 4 \\
\hline Braking time $(\mu \mathrm{s})$ & 4911 & 2282 & 1059 \\
\hline Braking distance $(\mu \mathrm{m})$ & 48,79 & 25,31 & 12,51 \\
\hline
\end{tabular}

Table 4

Braking of the rotor with ERF at high initial speed [8]

\begin{tabular}{|l|c|c|c|}
\hline$\omega_{0}(\mathrm{rad} / \mathrm{s})$ & \multicolumn{3}{|c|}{1,0} \\
\hline$E(\mathrm{kV} / \mathrm{mm})$ & 0 & 2 & 4 \\
\hline Braking time $(\mu \mathrm{s})$ & 8713 & 3646 & 1609 \\
\hline Braking distance $(\mu \mathrm{m})$ & 146,96 & 65,73 & 30,25 \\
\hline
\end{tabular}

Table 5

Braking of the rotor with MRF at low initial speed [8]

\begin{tabular}{|l|c|c|c|}
\hline$\omega_{0}(\mathrm{rad} / \mathrm{s})$ & \multicolumn{3}{|c|}{0,2} \\
\hline$H(\mathrm{kA} / \mathrm{m})$ & 0 & 100 & 200 \\
\hline Braking time $(\mu \mathrm{s})$ & 1528 & 554 & 312 \\
\hline Braking distance $(\mu \mathrm{m})$ & 4,97 & 2,16 & 1,26 \\
\hline
\end{tabular}

Table 6

Braking of the rotor with MRF at medium initial speed [8]

\begin{tabular}{|l|c|c|c|}
\hline$\omega_{0}(\mathrm{rad} / \mathrm{s})$ & \multicolumn{3}{|c|}{0,6} \\
\hline$H(\mathrm{kA} / \mathrm{m})$ & 0 & 100 & 200 \\
\hline Braking time $(\mu \mathrm{s})$ & 4827 & 1066 & 577 \\
\hline Braking distance $(\mu \mathrm{m})$ & 47,85 & 12,97 & 7,15 \\
\hline
\end{tabular}

Table 7

Braking of the rotor with MRF at high initial speed [8]

\begin{tabular}{|l|c|c|c|}
\hline$\omega_{0}(\mathrm{rad} / \mathrm{s})$ & \multicolumn{3}{|c|}{1,0} \\
\hline$H(\mathrm{kA} / \mathrm{m})$ & 0 & 100 & 200 \\
\hline Braking time $(\mu \mathrm{s})$ & 8517 & 1430 & 766 \\
\hline Braking distance $(\mu \mathrm{m})$ & 143,20 & 29,41 & 15,91 \\
\hline
\end{tabular}

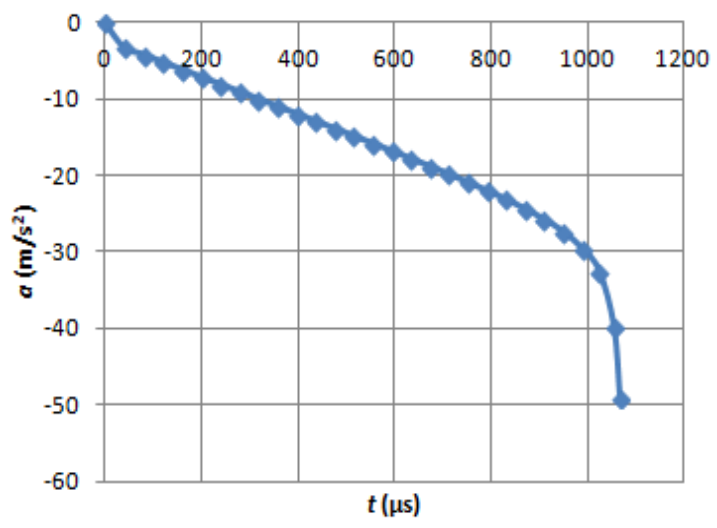

Fig. 14 Acceleration graph of braking with MRF [8]

\section{Experimental analysis}

These parts were used for experimental setup (Fig. 15): 1 - piezoelectric 3D deflector with spherical rotor; 2 - controller; 3 - Polytec Laser Doppler Vibrometer system OFV512/5000; 4 - linear amplifier EPA-104; 5 - signal generator Agilent 33220A; 6 - oscilloscope PicoScope 3424; 7 - PC with a PicoScope and Polytec software; 8 high voltage inverter CCF122C; 9 - DC power supply HY1803D; 10 - Mastech multimeter MS8218.

Operational frequency of the spherical actuator is $32,5 \mathrm{kHz}$. The maximum operational voltage of the ERF is $800 \mathrm{~V}$. The graphs of rotor operating modes using burst type vibrations with active and passive fluids are shown in the Figs. 16-17.

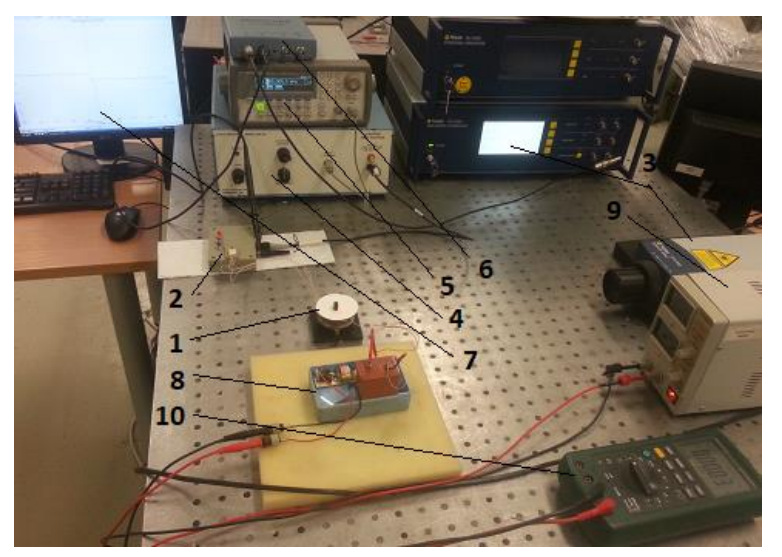

Fig. 15 Experimental setup

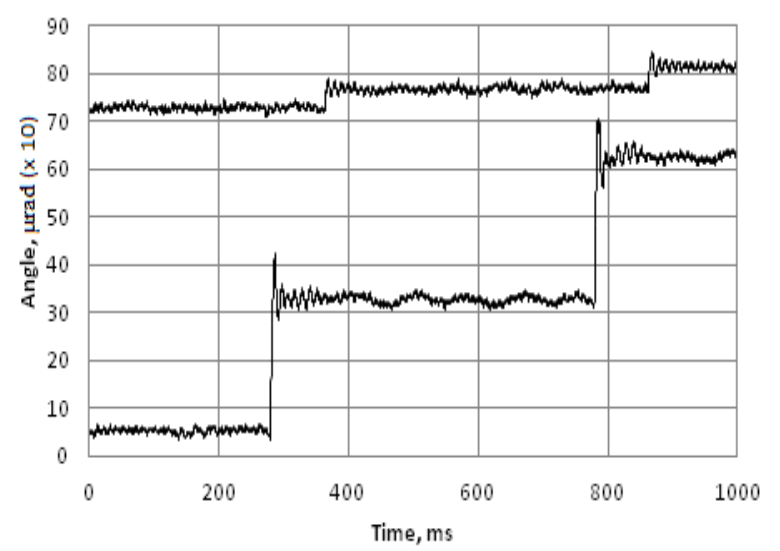

Fig. 16 Operating modes of the rotor: with activated ERF (at the top) and passive ERF 
Various stepped motions of the rotor can be obtained using different durations of burst type vibrations and voltage amplitudes (Fig. 18). One duration of vibrations is equal to 22 oscillating periods in the Figs. 16 and 17, which is equal to $677 \mu \mathrm{s}$.

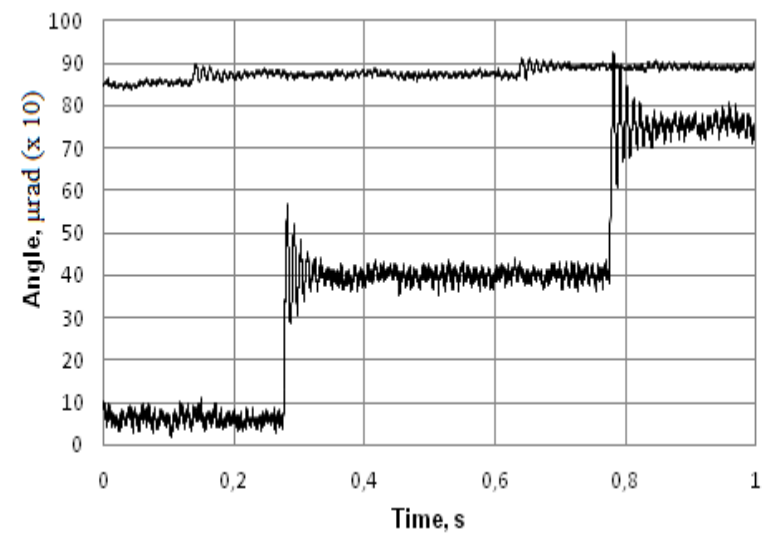

Fig. 17 Operating modes of the rotor: with activated MRF (at the top) and passive MRF

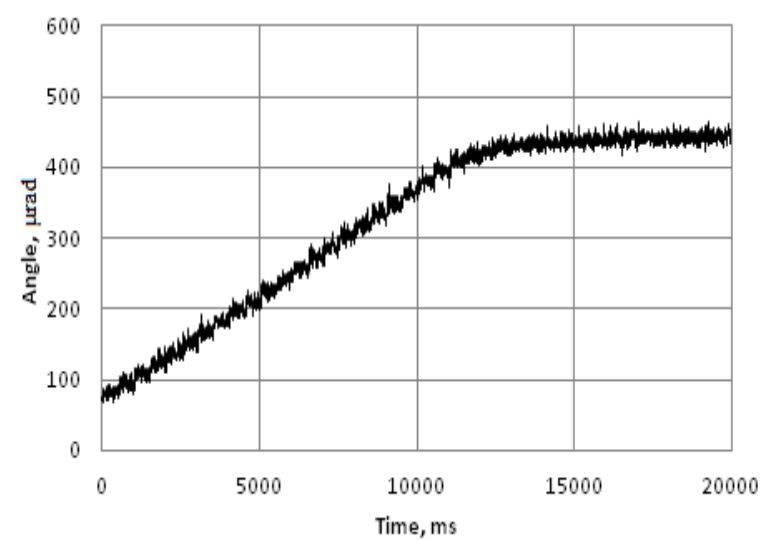

Fig. 18 Example of angular velocity control with voltage range from 0 to $800 \mathrm{~V}$

\section{Conclusions}

The stopping times are very similar to the response times of LID 3354s when an initial angular speed is $0,2 \mathrm{rad} / \mathrm{s}$ (Tab. 2). The stopping times are several times longer than the appropriate response times when the speeds of the ball are greater (Tab. 3-4). When the strength value of electric field varies from 0 to $4 \mathrm{kV} / \mathrm{mm}$ then the stopping times and distances differs approximately from $3\left(\omega_{0}=0,2 \mathrm{rad} / \mathrm{s}\right)$ to 5 $\left(\omega_{0}=1 \mathrm{rad} / \mathrm{s}\right)$ times.

The stopping times using MRF are lower than the appropriate response times (Tab. 5-7). When the strength value of magnetic field varies from 0 to $200 \mathrm{kA} / \mathrm{m}$ then the stopping times and distances differs approximately from 5 $\left(\omega_{0}=0,2 \mathrm{rad} / \mathrm{s}\right)$ to $10\left(\omega_{0}=1 \mathrm{rad} / \mathrm{s}\right)$ times. These statements are very similar to the ratios of real displacements; those are reached by the same excitation conditions when the chosen fluids are in active or passive modes.

\section{Acknowledgement}

This research was funded by the European Regional Development Fund according to the supported activity No. 01.2.2-LMT-K-718 under the project No. DOTSUT234 and by the Research Council of Lithuania under the project SmartTrunk, No. MIP-084/2015.

\section{References}

1. Junagal, K., Meena, R. S. 2016. Design and simulation of microstage having PZT MEMS actuator for 3D movement, International Conference on Advances in Computing, Comunications and Informatics, Jaipur: 21802185. https://doi.org/10.1109/ICACCI.2016.7732375.

2. Tzou, H. S., Lee, H. J., Arnold, S. M. 2004. Smart Materials, Precision Sensors/Actuators, Smart Structures and Structronic Systems, Journal of Mechanics of Advanced Materials and Structures 11: 367-393. https://doi.org/10.1080/15376490490451552.

3. Mavroidis, C., Bar-Cohen, Y., Bouzit, M. 2005. Chapter 19, Haptic interfaces using electrorheological fluids, Rutgers University. https://doi.org/10.1117/3.547465.ch19.

4. Electro-rheological fluid LID 3354s. Available from Internet: www.smarttec.co.uk/res/lid3354s\%20Rev\%202.pdf

5. MRF-140CG Magneto-Rheological Fluid. Available from Internet:

http://www.lordmrstore.com/lord-mr-products/mrf140cg-magneto-rheological-fluid.

6. Kubik, M., Machaček, O., Strecker, Z., Roupec, J., Mazurek, I. 2017. Design and testing of magnetorheological valve with fast force response time and great dynamic force range, Journal of Smart Materials and Structures 26: 1-9.

https://doi.org/10.1088/1361-665X/aa6066.

7. Wen, W., Huang, X., Sheng, P. 2008. Electrorheological fluids: structures and mechanisms, Journal of Soft Matter 4: 200-210. https://doi.org/10.1039/B710948M.

8. Augustaitis, A., Kulvietis, G., Jurènas, V., Djokoto, S. 2017. Kinematic characteristics of hollow ball under different braking conditions, Vibroengineering PROCEDIA 15: 7-12.

https://doi.org/10.21595/vp.2017.19391.

\section{A. Augustaitis, S. Djokoto, V. Jurènas, G. Kulvietis}

\section{CONTROL FEATURES OF 3D DEFLECTOR UNDER DIFFERENT BRAKING CONDITIONS}

S u m m a r y

The purpose of this article is to accurately evaluate the stopping distances of 3D deflector using tunable rheological features of smart fluids. Experimental characteristics of the chosen fluids are changed into smooth polynomial functions in accordance to the form of experimental graph and small total difference of ordinate values. Braking action and motion are modeled using a stepped approximation method, which is simple to use. This method was performed with Microsoft Excel program.

Keywords: rheological characteristics, electrorheological fluid (ERF), magnetorheological fluid (MRF), stepped approximation.

Received March 07, 2018 Accepted October 18, 2018 